\title{
Evidence of impaired bone quality in men with type 1 diabetes: a cross-sectional study
}

\author{
Unni Syversen ${ }^{1,2}$, Mats Peder Mosti ${ }^{1,3}$, Ida Maria Mynarek ${ }^{1}$, Trude Seselie Jahr Vedal ${ }^{1}$, Kristin Aasarød ${ }^{1,4}$, \\ Trude Basso ${ }^{5}$, Janne E Reseland ${ }^{6}$, Per Medbøe Thorsby ${ }^{7}$, Bjorn 0 Asvold ${ }^{2,8}$, Erik Fink Eriksen ${ }^{6}$ and \\ Astrid Kamilla Stunes ${ }^{1,3}$ \\ 'Department of Clinical and Molecular Medicine, Faculty of Medicine and Health Sciences, Norwegian University of Science and Technology (NTNU), \\ Trondheim, Norway \\ ${ }^{2}$ Department of Endocrinology, Trondheim University Hospital (St Olavs Hospital), Trondheim, Norway \\ ${ }^{3}$ Medical Clinic, Trondheim University Hospital (St Olavs Hospital), Trondheim, Norway \\ ${ }^{4}$ Department of Gastroenterology, Trondheim University Hospital (St Olavs Hospital), Trondheim, Norway \\ ${ }^{5}$ Department of Orthopedics, Trondheim University Hospital (St Olavs Hospital), Trondheim, Norway \\ ${ }^{6}$ Department of Biomaterials, University of Oslo, Oslo, Norway \\ ${ }^{7}$ Hormone Laboratory, Department of Medical Biochemistry, Oslo University Hospital, Aker, Oslo, Norway \\ ${ }^{8}$ K.G. Jebsen Center for Genetic Epidemiology, Department of Public Health and Nursing, NTNU, Trondheim, Norway
}

\begin{abstract}
Objective: Type 1 diabetes (T1D) is associated with substantial fracture risk. Bone mineral density (BMD) is, however, only modestly reduced, suggesting impaired bone microarchitecture and/or bone material properties. Yet, the skeletal abnormalities have not been uncovered. Men with T1D seem to experience a more pronounced bone loss than their female counterparts. Hence, we aimed to examine different aspects of bone quality in men with T1D.

Design and Methods: In this cross-sectional study, men with T1D and healthy male controls were enrolled. BMD (femoral neck, total hip, lumbar spine, whole body) and spine trabecular bone score (TBS) were measured by dual x-ray absorptiometry, and bone material strength index (BMSi) was measured by in vivo impact microindentation. $\mathrm{HbA}_{1 \mathrm{c}}$ and bone turnover markers were analyzed.

Results: Altogether, 33 men with T1D ( $43 \pm 12$ years) and 28 healthy male controls ( $42 \pm 12$ years) were included. Subjects with T1D exhibited lower whole-body BMD than controls $(P=0.04)$. TBS and BMSi were attenuated in men with T1D vs controls $(P=0.016$ and $P=0.004$, respectively), and T1D subjects also had a lower bone turnover. The bone parameters did not differ between subjects with or without diabetic complications.

Duration of disease correlated negatively with femoral neck BMD but not with

TBS or BMSi.

Conclusions: This study revealed compromised bone material strength and microarchitecture in men with T1D. Moreover, our data confirm previous studies which found a modest decrease in BMD and low bone turnover in subjects with T1D. Accordingly, bone should be recognized as a target of diabetic complications.
\end{abstract}
Key Words
- type 1 diabetes
- men
- trabecular bone score
- bone material strength index
- microindentation

Endocrine Connections (2021) 10, 955-964 


\section{Introduction}

Several studies have demonstrated increased fracture risk in both type 1 and 2 diabetes (T1D and T2D). A meta-analysis by Shah et al. $(n=27,300)$ showed that subjects with T1D displayed a three-fold higher relative risk for any fracture than normoglycemic subjects, and a four- to five-times higher relative risk of hip fracture in men and women, respectively (1). A meta-analysis from 2019 including $3,123,382$ participants confirmed that diabetes was associated with an elevated fracture risk, which was most pronounced at the hip, with an odds ratio of 5.3 and 1.6 in individuals with T1D and T2D, respectively (2).

Subjects with T1D also exhibit reduced bone mineral density (BMD) $(3,4)$; however, the increase in fracture risk is higher than the small reduction in BMD (4). BMD gives an estimation of bone quantity but provides little information about bone quality, which encompasses the structural and material properties of bone (5). Bone material properties are influenced by collagen properties, matrix mineralization, bone turnover, hydroxyapatite crystal size and heterogeneity (6).

To enhance the prediction of fracture risk, novel technologies for the assessment of bone microarchitecture and bone material strength have emerged. Trabecular bone score (TBS) is a surrogate measure of microarchitecture based on grey-level texture of spine dual $\mathrm{x}$-ray absorptiometry (DXA) images that have been shown to improve the prediction of fracture risk in combination with BMD (7). Moreover, TBS has been found to correlate with microstructural parameters measured by high-resolution peripheral quantitative CT (HRpQCT) (8). Additionally, advances in impact microindentation (IMI) technology have enabled in vivo assessment of bone material strength index (BMSi), at the tibial diaphysis, reflecting primarily cortical bone properties. A systematic review including 38 studies showed that IMI is a promising tool for the identification of individuals with primary osteoporosis and fractures and secondary osteoporosis due to various underlying systemic disorders (9).

Accumulation of advanced glycation end products (AGEs) has been proposed to affect bone quality in subjects with diabetes $(3,10)$. Pentosidine is a biomarker for AGEs that has been reported to increase over the course of diabetes (11), and serum levels correlate with prevalent fractures in T1D patients $(12,13)$. Thus, the measurement of pentosidine could potentially be useful for the identification of subjects at risk for fracture.

Few studies have addressed skeletal impairment in men with T1D, and these studies suggest that men experience a more marked bone affection than their female counterparts $(14,15)$. Men with T1D also have increased femoral neck fragility and decreased femoral strength assessed by QCT compared to controls $(16,17)$. The main objective of this study was, therefore, to assess bone quality by measurement of TBS and BMSi by IMI in men with T1D compared to healthy age-matched men. Moreover, we wanted to examine BMD, bone turnover, serum pentosidine, and the associations of TBS and BMSi with BMD, glycated hemoglobin $\left(\mathrm{HbA}_{1 \mathrm{c}}\right)$, duration of disease, and daily insulin dosage.

\section{Subjects and methods}

\section{Study design and study population}

This cross-sectional study was approved by the Regional Committee for Medical and Health Research Ethics in Central Norway. Consent was obtained from each subject after a full explanation of the purpose and nature of all procedures used. Men with verified T1D, 18-65 years, who were followed at the outpatient clinic, Department of Endocrinology, St. Olavs Hospital, Trondheim, Norway, were invited to participate. Exclusion criteria were major comorbidities, use of anti-osteoporotic drugs or medications known to interfere with bone health. The latter included glucocorticoids, anticonvulsant therapy, and anabolic steroids. Healthy, age-matched ( \pm 5 years) male controls were recruited by the subjects with T1D themselves (friends, colleagues) or among hospital employees. The participants were included from February to May 2013.

\section{Study size}

We expected a between-group difference in TBS of approximately $0.07 \pm 0.1$, and with a power of $80 \%$ and a significance level of 5\%, 32 participants in each group were sufficient to detect such differences.

\section{Study protocol}

Fasting morning blood samples were collected. Bodyweight was obtained using an electronic scale, height was measured using a wall-mounted stadiometer, and BMI $\left(\mathrm{kg} / \mathrm{m}^{2}\right)$ was calculated. All participants were interviewed for previous fractures, medical history, and medication; these data were supplemented by medical records. Data on Ca (from dairy products) and vitamin D intake (cod oil, omega-3

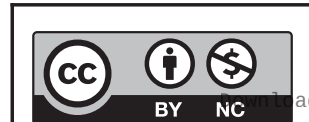


and fat fish), smoking, alcohol intake, physical activity, and parental osteoporosis were collected by interview. In subjects withT1D, the following data were collected from medical records: age at diagnosis, $\mathrm{HbA}_{1 \mathrm{c}}$ over the last 5 years, the current daily dosage of insulin, and diabetes complications.

\section{Biochemical analyses}

$\mathrm{HbA}_{1 \mathrm{c}}$ was analyzed in full blood. Serum 25-hydroxy vitamin D $(25 \mathrm{OH}(\mathrm{D}))$, parathyroid hormone $(\mathrm{PTH})$, ionized $\mathrm{Ca}$, phosphate, albumin, $\mathrm{Mg}$, creatinine, folic acid, ferritin, testosterone and sex hormone-binding globulin (SHBG) were analyzed at the Department of Biochemistry, St. Olavs Hospital. Free testosterone was calculated from total testosterone, SHBG, and albumin concentrations (18). Serum pentosidine was measured by an ELISA (Nordic BioSite, Täby, Sweden). The bone resorption marker C-terminal telopeptide of type 1 collagen (CTX-I) and formation markers total procollagen of type $1 \mathrm{~N}$-terminal propeptide (P1NP) and osteocalcin were measured in serum by electrochemiluminescence immunoassays at the Hormone Laboratory, Oslo University Hospital. Leptin, osteoprotegerin (OPG), sclerostin and Dickopf-1 in serum were analyzed using multianalyte profiling Milliplex MAP assay (Millipore). All analyses were done according to the manufacturers' instructions.

\section{Dual x-ray absorptiometry}

Hip, lumbar spine (L1-L4) and whole-body BMD along with whole-body fat and lean mass were measured by DXA, applying Hologic Discovery A S/N 83817 (Hologic, Bedford, MA, USA). Z-scores were used for group comparisons. TBS of the lumbar spine (L1-L4) was calculated using the TBS iNsight $^{\oplus}$ software version 2.1.0.0 (Medimaps, Pessac, France).

\section{Impact microindentation}

IMI was performed in a subgroup of the participants using Osteoprobe (Active Life Scientific, St. Barbara, CA, USA) (19). The probe was applied on the middle third of the medial tibial diaphysis under local anesthesia (1\% lidocaine). Six indentations were performed, keeping the indenter perpendicular to the bone surface and slightly moved between each indentation. The indentation depth recorded was standardized against indentations on a calibration phantom and repeated for each participant.
BMSi was calculated by the Osteoprobe software as $100 \times$ the ratio of the average indentation distance in the phantom.

\section{Statistics}

All statistics were performed using the IBM SPSS statistics version 22 software (IBM). Figures were made using the GraphPad Prism 5 software (GraphPad). All variables were tested for skewness and kurtosis and for normal distribution by the Shapiro-Wilk test. For group comparisons, a two-tailed independent sample $t$-test was applied for normally distributed data, and Mann-Whitney $U$-test for non-normally distributed data and $\chi^{2}$ tests when appropriate. Associations were analyzed using Spearman correlation, as this is considered more appropriate for a relatively small sample size. Data are presented as mean \pm S.D. or median (interquartile range (IQR)), depending on normal distribution or not. ORs are presented as crude values with $95 \% \mathrm{CI}$. A two-sided $P$-value $\leq 0.05$ was considered significant.

\section{Results}

Of the 35 men with T1D enrolled, 2 were excluded because of known osteoporosis treated with bisphosphonates. The intention was to include the same number in both groups, however, 5 of the 33 enrolled men in the control group withdrew from the study. Finally, 33 men with diabetes (20-62 years old) and 28 healthy age-matched controls (23-63 years old) were included. See flow chart in Supplementary Materials (see section on supplementary materials given at the end of this article).

\section{Characteristics of the study population}

Characteristics are shown in Table 1. The groups did not differ in age, height, weight, body fat $\%$, lean mass, level of physical activity, or the number of previous fractures. All fractures, except one in each group, were of high energy. Four men with T1D (12\%) and two controls (7\%) reported osteoporosis and/or fractures among patients. Subjects with T1D had higher BMI and a higher frequency of past smoking. Controls reported higher current alcohol consumption. The estimated intake of $\mathrm{Ca}$ and vitamin $\mathrm{D}$ was similar between the groups (data not shown). Twelve (36\%) were diagnosed with T1D before 15 years of age. Thirteen subjects (39\%) had one or more mild diabetic complications (eye complications $n=9$, neuropathy $n=1$, $>2$ complications $n=3$ ). Men with T1D were treated 
Table 1 Characteristics in men with type 1 diabetes and age-matched control subjects.

\begin{tabular}{|c|c|c|c|}
\hline Variables & $\begin{array}{c}\text { Type } 1 \\
\text { diabetes } \\
\text { patients } \\
(n=33)\end{array}$ & $\begin{array}{c}\text { Control } \\
\text { subjects } \\
(n=28)\end{array}$ & P-value \\
\hline Age (years) & $42.7 \pm 12.1$ & $41.8 \pm 12.0$ & 0.744 \\
\hline Age at diagnosis (years) & $19.3 \pm 11.6$ & NA & NA \\
\hline $\begin{array}{l}\text { Duration of disease } \\
\text { (years) }\end{array}$ & $23.0 \pm 10.2$ & NA & NA \\
\hline $\begin{array}{l}\text { Daily dosage of } \\
\text { insulin (IU) }\end{array}$ & $62.7 \pm 22.8$ & NA & NA \\
\hline \multicolumn{4}{|l|}{ Anthropometrics } \\
\hline Height (cm) & $182 \pm 5.8$ & $182 \pm 6.0$ & 0.248 \\
\hline Weight (kg) & $84.8 \pm 10.6$ & $80.6 \pm 8.6$ & 0.099 \\
\hline BMI $\left(k g / m^{2}\right)$ & $25.9 \pm 3.2$ & $24.1 \pm 2.4$ & 0.017 \\
\hline Body fat (\%) & $18.6 \pm 4.2$ & $17.4 \pm 4.0$ & 0.466 \\
\hline Body lean mass (kg) & $67.3 \pm 6.6$ & $64.7 \pm 6.4$ & 0.120 \\
\hline \multicolumn{4}{|l|}{ Lifestyle factors } \\
\hline Current smoker & $6(18.2)$ & $2(7.1)$ & 0.264 \\
\hline Current snus user & $1(3.0)$ & 5 (17.9) & 0.088 \\
\hline Past smoker/snus user & $9(27.3)$ & $2(7.1)$ & 0.036 \\
\hline Alcohol (units/week) & $1.5(0.5-6.0)$ & $4.4(2.0-6.9)$ & 0.04 \\
\hline \multicolumn{4}{|l|}{ Physical activity > 30 min } \\
\hline 0 times/week & $2(6)$ & 0 & \\
\hline 1-2 times/week & $9(27)$ & $7(25)$ & 0.391 \\
\hline$\geq 3$ times/week & $27(67)$ & $21(75)$ & \\
\hline Previous fractures ${ }^{a}$ & $15(46)$ & $17(61)$ & 0.38 \\
\hline
\end{tabular}

Data are in mean \pm S.D., $n$ (\%) or median (interquartile range). Bold indicates statistical significance.

${ }^{a}$ All were high-energy fractures, except one in each group.

with the following drugs: simvastatin $n=6$, angiotensin II receptor blockers (ARBs) $n=5$, antihistamines $n=4$, angiotensin II converting enzyme (ACE) inhibitors $n=3$, Ca antagonist $n=1$, acetylsalicylic acid $n=5$, proton pump inhibitors $n=2$, thyroxine $n=2$, carbamazepine $n=1$. Antihistamines were used by six controls.

\section{Biochemical analyses}

Table 2 shows the results of all biochemical analyses. Mean $\mathrm{HbA}_{1 \mathrm{c}}$ levels were $8.0 \pm 0.8 \%(63.8 \pm 8.9 \mathrm{mmol} / \mathrm{mol})$ and $5.3 \pm 0.3 \%(33.9 \pm 2.9 \mathrm{mmol} / \mathrm{mol})$ in men with T1D and controls, respectively $(P<0.001)$. The 5 -year $\mathrm{HbA}_{1 \mathrm{c}}$ average among subjects with T1D was $7.8 \pm 0.8 \%$ $(62.9 \pm 8.8 \mathrm{mmol} / \mathrm{mol})$. Levels of $25(\mathrm{OH}) \mathrm{D}$, PTH, ionized Ca, phosphate, folic acid and ferritin were similar between the groups. Mean 25(OH)D levels were $57.0 \pm 25.8$ and $53 \pm 18.5$ $\mathrm{nmol} / \mathrm{L}$ in subjects with T1D and controls, respectively. Seven (21\%) men with T1D had vitamin D deficiency
Table 2 Biochemical analyses in men with type 1 diabetes and age-matched control subjects.

\begin{tabular}{|c|c|c|c|}
\hline & $\begin{array}{l}\text { Men with type } 1 \\
\text { diabetes }(n=33)\end{array}$ & $\begin{array}{c}\text { Control subjects } \\
(n=28)\end{array}$ & P-value \\
\hline $\mathrm{HbA}_{1 \mathrm{c}}(\%)$ & $8.0 \pm 0.8$ & $5.3 \pm 0.3$ & $<0.001$ \\
\hline $\begin{array}{l}\mathrm{HbA}_{1 \mathrm{c}} \\
(\mathrm{mmol} / \mathrm{mol})\end{array}$ & $63.8 \pm 8.9$ & $33.9 \pm 2.9$ & $<0.001$ \\
\hline 5-year $\mathrm{HbA}_{1 \mathrm{c}}(\%)$ & $7.8 \pm 0.8$ & NA & NA \\
\hline $\begin{array}{l}\text { 5-year } \mathrm{HbA}_{1 \mathrm{c}} \\
(\mathrm{mmol} / \mathrm{mol})\end{array}$ & $62.9 \pm 8.8$ & NA & NA \\
\hline $\mathrm{Ca}(\mathrm{mmol} / \mathrm{L})$ & $2.34 \pm 0.08$ & $2.35 \pm 0.10$ & 0.717 \\
\hline $\begin{array}{l}\text { Ionized Ca } \\
(\mathrm{mmol} / \mathrm{L})\end{array}$ & $1.22 \pm 0.03$ & $1.22 \pm 0.03$ & 0.961 \\
\hline $\begin{array}{l}\text { Phosphate } \\
\text { (nmol/L) }\end{array}$ & $0.96 \pm 0.14$ & $1.02 \pm 0.17$ & 0.162 \\
\hline $\mathrm{Mg}(\mathrm{mmol} / \mathrm{L})$ & $0.79 \pm 0.06$ & $0.85 \pm 0.05$ & $<0.001$ \\
\hline Albumin (g/L) & $43.8 \pm 2.35$ & $46.3 \pm 1.73$ & $<0.001$ \\
\hline PTH (pmol/L) & $3.4(2.9-4.1)$ & $3.5(2.9-4.6)$ & 0.839 \\
\hline $25 \mathrm{OH}(\mathrm{D})(\mathrm{nmol} / \mathrm{L})$ & $57.0 \pm 25.8$ & $53.0 \pm 18.5$ & 0.502 \\
\hline Ferritin $(\mu \mathrm{g} / \mathrm{L})$ & 132 (85-179) & $121(82-282)$ & 0.981 \\
\hline $\begin{array}{l}\text { Folic acid } \\
(\mathrm{nmol} / \mathrm{L})\end{array}$ & $17.0(15.0-22.0)$ & $16.5(15.0-20.3)$ & 0.218 \\
\hline $\begin{array}{l}\text { Creatinine } \\
(\mu \mathrm{mol} / \mathrm{L})\end{array}$ & $71.9 \pm 14.3$ & $79.5 \pm 9.10$ & 0.024 \\
\hline SHBG (nmol/L) & $60.7 \pm 20.7$ & $39.7 \pm 16.2$ & $<0.001$ \\
\hline $\begin{array}{l}\text { Testosterone } \\
(\mathrm{nmol} / \mathrm{L})\end{array}$ & $22.9 \pm 6.83$ & $18.9 \pm 4.55$ & 0.013 \\
\hline $\begin{array}{l}\text { Free testosterone } \\
(\mathrm{nmol} / \mathrm{L})\end{array}$ & $0.34 \pm 0.11$ & $0.35 \pm 0.07$ & 0.657 \\
\hline $\mathrm{P} 1 \mathrm{NP}(\mu \mathrm{g} / \mathrm{L})$ & $35.0(30.0-48.8)$ & $41.0(35.2-55.5)$ & 0.080 \\
\hline CTX-1 ( $\mu \mathrm{g} / \mathrm{L})$ & $0.25(0.22-0.39)$ & $0.43(0.33-0.56)$ & 0.001 \\
\hline $\mathrm{OC}$ (nmol/L) & $0.60(0.48-1.00)$ & $1.00(0.78-1.30)$ & 0.012 \\
\hline OPG $(\mu \mathrm{g} / \mathrm{L})$ & $0.18(0.14-0.25)$ & $0.17(0.13-0.19)$ & 0.348 \\
\hline Sclerostin $(\mu \mathrm{g} / \mathrm{L})$ & $0.37(0.25-0.69)$ & $0.39(0.25-0.63)$ & 0.799 \\
\hline Dickopf-1 ( $\mu \mathrm{g} / \mathrm{L})$ & $0.93 \pm 0.04$ & $1.05 \pm 0.04$ & 0.233 \\
\hline Leptin $(\mu \mathrm{g} / \mathrm{L})$ & $0.48(0.21-0.78)$ & $0.51(0.31-0.82)$ & 0.710 \\
\hline $\begin{array}{l}\text { Pentosidine } \\
(\mu \mathrm{g} / \mathrm{L})\end{array}$ & $73.6(51.1-129.6)$ & 75.9 (53.9-97.5) & 0.962 \\
\hline
\end{tabular}

Values are in mean \pm S.D.or median (interquartile range), depending on distribution.

CTX-1, C-terminal telopeptide cross-linked type 1 collagen; OC, osteocalcin; OPG, osteoprotegerin; P1NP, N-terminal propeptide type 1 collagen; PTH, parathyroid hormone; SHBG, sex hormone-binding globulin.

$(25(\mathrm{OH}) \mathrm{D}<30 \mathrm{nmol} / \mathrm{L}), 4(12 \%)$ had levels between 30 and $50 \mathrm{mmol} / \mathrm{L}$, and $22(67 \%)$ had levels above $50 \mathrm{pmol} / \mathrm{L}$. The corresponding numbers in the control group were: $2(7 \%)$, 12 (43\%) and 14 (50\%) (overall $P=0.02)$. Mean Mg level was lower in subjects with T1D compared to controls $(0.79 \pm 0.06$ and $0.85 \pm 0.05 \mathrm{mmol} / \mathrm{L}, P<0.001)$. Testosterone and SHBG levels were higher in the subjects with T1D, however, calculated free testosterone did not differ between the groups. CTX-1, osteocalcin and P1NP were lower in men with T1D compared to controls, however, not significant for the latter $(P=0.08)$. Levels of leptin, OPG, sclerostin, Dickopf-1, and pentosidine were similar. https://ec.bioscientifica.com

https://doi.org/10.1530/EC-21-0193 (c) 2021 The authors Published by Bioscientifica Ltd

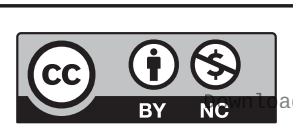

This work is licensed under a Creative Commons Attribution-NonCommercial 4.0 International License. ded from Bioscientifica.com at 04/26/2023 10:44:24AM via free access 
Bone mineral density, trabecular bone score and bone material strength index

Men with T1D exhibited lower Z-scores than controls at all sites but was significant only for whole body, Z-score, $-0.82 \pm 1.00$ and $-0.32 \pm 0.74$, respectively, $P=0.03$ (Fig. $1 \mathrm{~A}$, $B$ and Table 3). Spine TBS was significantly lower in subjects with T1D compared to controls $(1.40 \pm 0.1$ vs $1.46 \pm 0.09$, $P=0.016)$, also when comparing only vertebrae with the lowest TBS ( $1.30 \pm 0.10$ vs $1.40 \pm 0.11, P=0.001)$ (Fig. 1C).

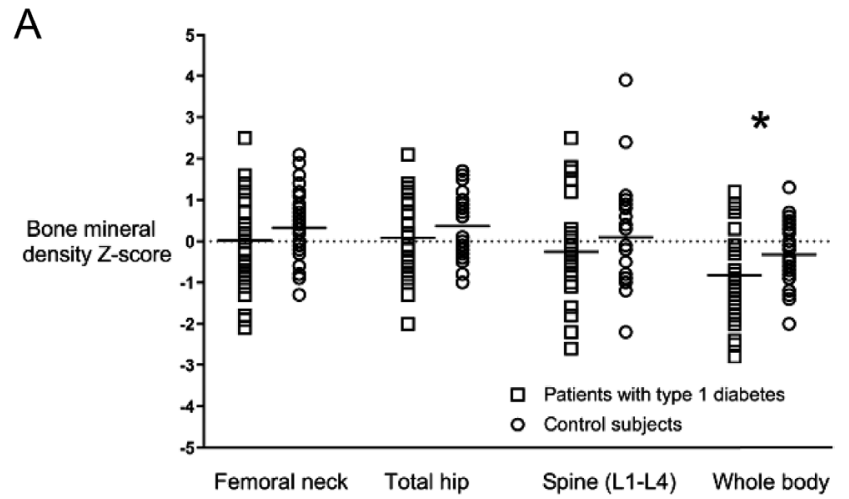

B
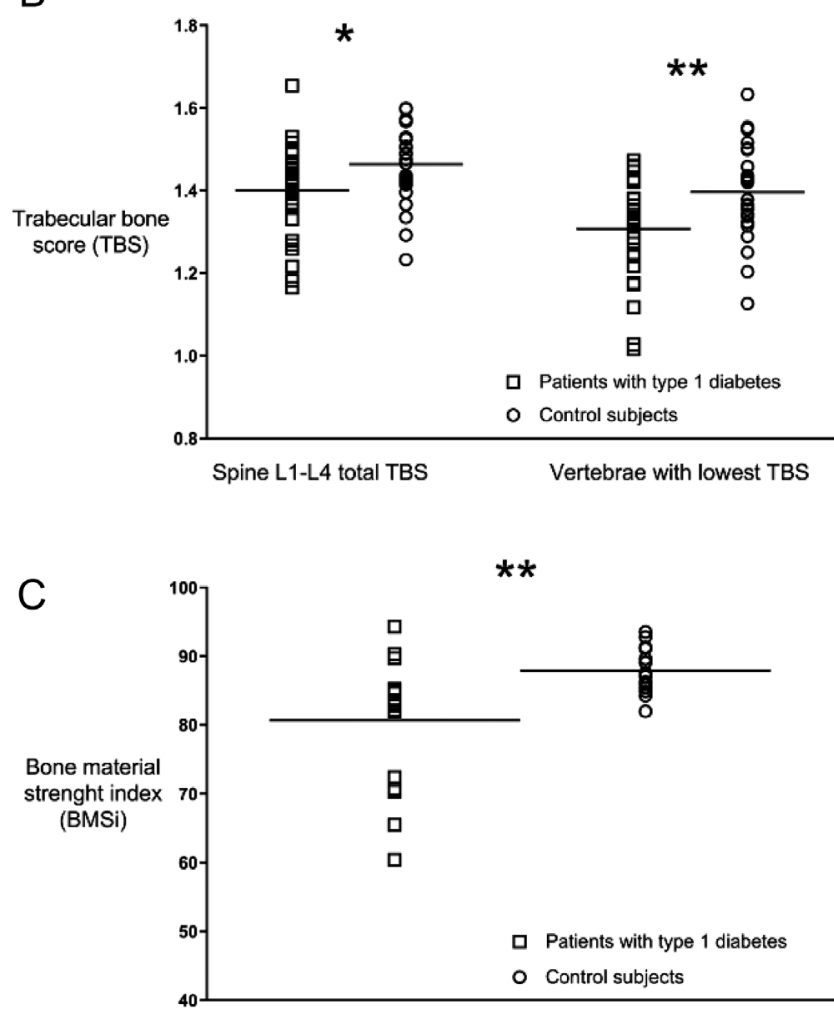

Figure 1

Areal bone mineral density Z-score (A), trabecular bone score (B) and bone material strength index $(C)$ in male subjects with type 1 diabetes and control subjects.
Table 3 Bone mineral density (BMD) in men with type 1 diabetes and age-matched control subjects.

\begin{tabular}{|c|c|c|c|}
\hline & $\begin{array}{l}\text { Men with type } 1 \\
\text { diabetes }(n=33)\end{array}$ & $\begin{array}{c}\text { Control } \\
\text { subjects }(n=28)\end{array}$ & P-value \\
\hline \multicolumn{4}{|l|}{$\mathrm{BMD}\left(\mathrm{g} / \mathrm{cm}^{2}\right)$} \\
\hline Femoral neck & $0.86 \pm 0.17$ & $0.90 \pm 0.13$ & 0.284 \\
\hline Total hip & $1.01 \pm 0.16$ & $1.05 \pm 0.12$ & 0.329 \\
\hline Lumbar spine & $1.04 \pm 0.16$ & $1.07 \pm 0.13$ & 0.341 \\
\hline Whole body & $1.11 \pm 0.10$ & $1.15 \pm 0.08$ & 0.076 \\
\hline \multicolumn{4}{|l|}{ BMD Z-score } \\
\hline Femoral neck & $0.02 \pm 1.18$ & $0.90 \pm 0.13$ & 0.251 \\
\hline Total hip & $0.08 \pm 0.99$ & $0.36 \pm 0.75$ & 0.225 \\
\hline Lumbar spine & $-0.26 \pm 1.39$ & $0.10 \pm 1.23$ & 0.300 \\
\hline Whole body & $-0.82 \pm 1.00$ & $-0.32 \pm 0.74$ & 0.032 \\
\hline
\end{tabular}

Data are presented in mean \pm S.D.

IMI was performed in a subgroup of participants; 18 men with T1D and 14 controls (age: $43.6 \pm 9.0$ years and $38.6 \pm 3.4$ years; BMI $26.2 \pm 3.7 \mathrm{~kg} / \mathrm{m}^{2}, 24.1 \pm 2.9 \mathrm{~kg} / \mathrm{m}^{2}$, respectively). Median BMSi in men with T1D was 83.2 (72.0-85.1) vs controls 87.4 (85.3-91.2), $P=0.004$ (Fig. 1D).

No significant differences in BMD, TBS or BMSi were seen between those diagnosed with T1D before or after 15 years of age (total hip Z-score: $0.10 \pm 0.70$ vs $0.04 \pm 1.16$, $P=0.843$; TBS: $1.38 \pm 0.08$ vs $1.41 \pm 0.12, P=0.567$; BMSi: 84.7 (76.9-87.5) vs 82.5 (70.8-85.0), $P=0.376)$. The bone parameters did not differ between subjects with or without diabetic complications (total hip Z-score: $0.45 \pm 0.82$ vs $-0.12 \pm 1.05, P=0.093$; TBS: $1.40 \pm 0.12$ vs $1.40 \pm 0.10$, $P=0.921$; BMSi: 84.7 (70.7-90.3) vs 83.1 (72.4-85.0), $P=0.904)$. In participants with a history of fracture, the bone parameters were similar to those without fracture within both groups.

\section{Correlations in the T1D group}

Correlations are shown in Table 4. No correlation was seen between TBS and BMI. BMD at all sites correlated positively with TBS. Neither BMD nor TBS was associated with BMSi. No significant correlations were observed between $\mathrm{HbA}_{1 \mathrm{c}}$ (current and average of last 5 years) and BMD or TBS. Current $\mathrm{HbA}_{1 \mathrm{c}}$ was positively associated with BMSi (rho $=0.532, P=0.02$ ), also after correction for age (rho $=0.540, P=0.03)$. No correlation was found between BMSi and average $\mathrm{HbA}_{1 \mathrm{c}}$ levels in the past 5 years. Both current $\mathrm{HbA}_{1 \mathrm{c}}$ level and BMSi were positively associated with daily insulin dosage (rho $=0.39, P=0.03$ and rho $=0.566, P=0.02$, respectively). No correlations were seen between insulin dosage and BMD or TBS. Levels of $25(\mathrm{OH}) \mathrm{D}$ and $\mathrm{Mg}$ were not associated with any of the bone parameters. Duration of disease and age correlated

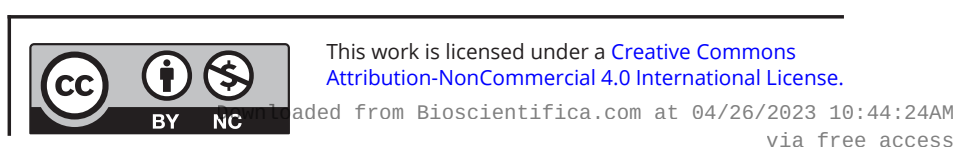


Table 4 Correlations in men with type 1 diabetes.

\begin{tabular}{|c|c|c|c|c|c|c|}
\hline & \multicolumn{3}{|c|}{ TBS $^{\mathbf{a}}$} & \multicolumn{3}{|c|}{ BMSí $^{\mathbf{b}}$} \\
\hline & Rho & $P$-value & Shared variance (\%) & Rho & $P$-value & Shared variance (\%) \\
\hline $\mathrm{BMI}\left(\mathrm{kg} / \mathrm{m}^{2}\right)$ & -0.284 & 0.121 & 8.1 & 0.201 & 0.423 & 4.0 \\
\hline \multicolumn{7}{|l|}{$\mathrm{BMD}\left(\mathrm{g} / \mathrm{cm}^{2}\right)$} \\
\hline Lumbar spine & 0.495 & 0.004 & 24.5 & -0.091 & 0.720 & 0.8 \\
\hline Femoral neck & 0.529 & 0.002 & 28.0 & -0.154 & 0.542 & 2.4 \\
\hline Total hip & 0.501 & 0.003 & 25.1 & -0.069 & 0.785 & 0.5 \\
\hline Whole body & 0.591 & $<0.001$ & 34.9 & -0.194 & 0.440 & 3.8 \\
\hline TBS & & & & -0.226 & 0.367 & 5.1 \\
\hline \multicolumn{7}{|l|}{$\mathrm{HbA}_{1 \mathrm{c}}(\mathrm{mmol} / \mathrm{L})$} \\
\hline Current & -0.311 & 0.095 & 9.7 & 0.532 & 0.023 & 28.3 \\
\hline 5-year mean & -0.284 & 0.116 & 8.1 & 0.362 & 0.140 & 13.1 \\
\hline \multicolumn{7}{|l|}{ Insulin } \\
\hline \multirow[t]{3}{*}{ Daily dose (IU) } & -0.337 & 0.069 & 11.4 & 0.566 & 0.018 & 32.0 \\
\hline & \multicolumn{3}{|c|}{ HbA1c (mmol/L) current } & \multicolumn{3}{|c|}{ Duration of disease } \\
\hline & Rho & $P$-value & Shared variance $(\%)$ & Rho & $P$-value & Shared variance (\%) \\
\hline Insulin & & & & & & \\
\hline Daily dose (IU) & 0.399 & 0.032 & 15.9 & 0.192 & 0.300 & 3.7 \\
\hline \multicolumn{7}{|l|}{$\mathrm{BMD}\left(\mathrm{g} / \mathrm{cm}^{2}\right)$} \\
\hline Lumbar spine & -0.125 & 0.503 & 1.6 & -0.111 & 0.546 & 1.2 \\
\hline Femoral neck & -0.001 & 0.995 & $<0.001$ & -0.371 & 0.037 & 13.8 \\
\hline Total hip & -0.064 & 0.731 & 0.4 & -0.285 & 0.114 & 8.1 \\
\hline Whole body & -0.150 & 0.421 & 2.3 & -0.223 & 0.219 & 5.0 \\
\hline TBS & -0.311 & 0.095 & 9.7 & -0.299 & 0.103 & 8.9 \\
\hline BMSi & 0.532 & 0.023 & 28.3 & 0.367 & 0.147 & 13.5 \\
\hline
\end{tabular}

$\operatorname{TBS}^{\mathrm{a}}(n=33), \mathrm{BMSi}^{\mathrm{b}}(n=18)$.

$\mathrm{BMD}$, bone mineral density; BMSi, bone material strength index, TBS, trabecular bone score.

negatively with femoral neck BMD (rho $=-0.37, P=0.04$ and rho=-0.49, $P=0.004)$. No correlation was found between the duration of disease and bone quality indices.

\section{Discussion}

Subjects with T1D display an increased risk for fragility fractures, but the underlying skeletal abnormalities are still elusive. Here we show that men with T1D exhibit modestly lower BMD than male controls, significantly only for whole-body Z-score. Moreover, TBS and BMSi were reduced compared to non-diabetic controls, indicating impairment of bone microarchitecture and bone material properties. Levels of bone turnover markers and $\mathrm{Mg}$ were also lower among men with T1D, whereas pentosidine levels did not differ between the groups.

The lower BMD in male subjects with T1D corresponds with previous studies $(20,21,22)$. In contrast to the metaanalyses by Vestergard et al. and Pan et al. $(4,22)$, we found that age and duration of disease were associated with poorer absolute BMD but only at the femoral neck. Given the small reduction in $\mathrm{BMD}$, it is reasonable that it does not explain the high fracture risk in T1D. Hence, other determinants of bone strength need to be addressed. DXA-derived TBS gives an indirect measure of the microarchitecture at the lumbar spine. A meta-analysis including 12 studies reported inferior TBS in individuals with T2D (23), whereas TBS in subjects with T1D has been less explored. We observed a significantly lower TBS among men with T1D compared to healthy controls. This is in accordance with Karytska et al. who described lower TBS in men with T1D compared to healthy controls (24), and with Shah et al. who reported that adults of both genders with T1D displayed lower TBS than controls (25). On the other hand, Neumann et al. observed reduced TBS only among T1D subjects with prevalent fractures (15).

BMD and TBS reflect bone quantity and structure but give little information about material properties of bone, which significantly contribute to bone strength. Previously, this could only be examined ex vivo in a bone biopsy. The introduction of IMI has enabled a direct evaluation of bone material properties at the tissue level in vivo. A systematic review concluded that IMI is a promising tool for the assessment of bone fragility, particularly in secondary osteoporosis (9). Accordingly, several studies have reported reduced BMSi among subjects with T2D $(26,27,28)$ in spite of normal or even elevated BMD. Lower BMSi and TBS have also been demonstrated in men with T2D (29). We show for the first time that men with T1D display significantly 
lower BMSi than healthy controls, underscoring that compromised bone material properties contribute to the increased fracture risk seen in these subjects. In contrast, in premenopausal women with T1D, BMSi did not differ from controls (30). Whether this is attributed to sex differences remains to be elucidated.

Most studies have reported low bone turnover in subjects with diabetes. In line with this, we observed lower levels of the bone resorption marker CTX-1 and the bone formation markers osteocalcin and P1NP among men with T1D, although not significant for the latter. A systematic review and meta-analysis of 66 studies concluded that both subjects with T1D and T2D displayed low bone turnover (31). The cellular mechanisms responsible are poorly understood, but several factors have been invoked. Insulin deficiency and hyperglycemia seem to exert direct effects on bone homeostasis by inhibiting bone formation (3). This could be mediated by the wnt inhibitors Dickkopf-1 and sclerostin (32). Accordingly, higher levels of Dickkopf- 1 have been reported in children and adolescents with T1D (33). Moreover, Pacicca et al. found that elevated glucose induced a rise in sclerostin expression in osteocytes from diabetic rats (34). We, however, did not observe any difference in levels of Dickkopf- 1 or sclerostin between the two groups.

Long-term hyperglycemia induces non-enzymatic glycosylation, resulting in an accumulation of AGEs, which also influences bone formation negatively (35). Cross-linking of AGEs within collagen fibers might deteriorate the mechanical properties of the bone (11). In spite of the differences in bone quality in the present study, no difference in serum pentosidine levels was discernible between men with T1D and controls. Neumann et al. reported that serum pentosidine was associated with prevalent fractures, independent of BMD, in men and postmenopausal women with T1D (13). Notably, elevated levels of pentosidine are also seen in subjects with low impact hip fracture (36) and may be attributed to aging, inflammation, renal failure, oxidative stress, dietary factors, cigarette smoking and chronic alcohol consumption (37).

Given that accumulation of AGEs is proposed as an important mechanism underlying skeletal impairment in T1D, one would expect a negative correlation between $\mathrm{HbA}_{1 \mathrm{c}}$ and skeletal parameters in the patient group. However, in line with previous studies, neither current nor 5 years average $\mathrm{HbA}_{1 \mathrm{c}}$ showed association with BMD or TBS $(15,38)$. Unexpectedly, present $\mathrm{HbA}_{1 \mathrm{c}}$ was positively associated with BMSi in the diabetes group even after correction for age, whereas no correlation was observed with average of 5 years $\mathrm{HbA}_{1 \mathrm{c}}$. Given the positive association between insulin dosage and both current $\mathrm{HbA}_{1 \mathrm{c}}$ and $\mathrm{BMSi}$, we speculate that the positive correlation between $\mathrm{HbA}_{1 \mathrm{c}}$ and BMSi possibly reflects an anabolic effect of insulin on bone. In accordance with this, insulin given to male rats with T1D maintained mechanical properties of bones (39). Ivaska et al. also demonstrated a potential anabolic effect of insulin on bone turnover in humans (40). Farr et al. observed no correlation between $\mathrm{BMSi}$ and single-screen visit $\mathrm{HbA}_{1 \mathrm{c}}$ but a negative correlation with average of 10 years $\mathrm{HBA}_{1 \mathrm{c}}$ in postmenopausal women with T2D (26). This indicates that long-term hyperglycemia may affect bone quality. On the other hand Farr et al. reported that the duration of disease was not related to BMSi (26), which corresponds with our findings.

Several other factors could affect bone adversely, including hypomagnesemia, Ca and vitamin D deficiency, and medications. Mg deficiency is reported to occur among $25-39 \%$ of individuals with diabetes (41). Consistent with this, we observed significantly lower mean $\mathrm{Mg}$ level in men with T1D compared to controls. In a study of middleaged Caucasian men, low serum $\mathrm{Mg}(<0.74 \mathrm{nmol} / \mathrm{L}(1.8$ $\mathrm{mg} / \mathrm{dL})$ ) was strongly and independently associated with increased fracture risk (42). Hypomagnesemia promotes bone loss via direct effects on bone cells and indirectly by an impact on PTH (43). Moreover, insufficient Mg may affect bone quality by the formation of larger and more fragile hydroxyapatite crystals (44). Thus, inadequate $\mathrm{Mg}$ levels may contribute to the inferior bone quality observed in individuals with diabetes.

Lower levels of 25(OH)D have been reported both in subjects with T1D and T2D compared to controls (45). We did not observe any difference in mean $25(\mathrm{OH}) \mathrm{D}$, Ca and PTH levels between the groups. The groups had a similar dietary intake of vitamin D and Ca. A higher proportion of men with T1D displayed vitamin D deficiency. Levels of $25(\mathrm{OH}) \mathrm{D}$, however, did not correlate with any of the bone parameters in the patient group.

Theuseofdrugsprescribedtotreathypercholesterolemia and hypertension (e.g. statins, ACE inhibitors, ARBs, Ca channel blockers) was more common in the diabetes group. About 30 and $25 \%$ were treated with statins and antihypertensives, respectively. A preponderance of evidence suggests that statins are associated with an increment in BMD (46). On the other hand, the use of ACE inhibitors, but not ARBs, was associated with a small but significantly greater bone loss at the total hip over 4 years in older men (47). Based on these data, it is unlikely that medication use can explain the differences in bone quality in the current study.

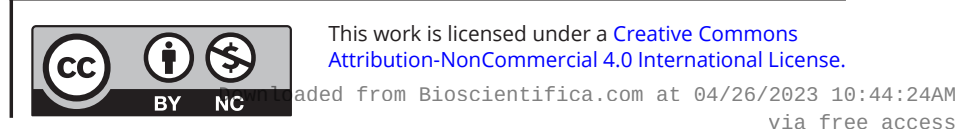


Finally, the presence of microvascular complications as retinopathy, nephropathy, and neuropathy could contribute to the increased risk of fragility fractures in subjects with T1D. The burden of complications was, however, low among our participants, and TBS and BMSi did not differ between those with or without diabetes complications.

Our study addresses a complication of diabetes that is neglected. There are so far no guidelines on how to deal with osteoporosis in individuals with diabetes. Since fracture risk is underestimated by the use of $\mathrm{BMD}$, additional tools are required. We show that DXA-derived TBS and IMI are valuable and simple tools for the assessment of bone quality in this patient group that will improve the estimation of fracture risk.

The study has limitations. The sample size was relatively small, and the cross-sectional study design cannot be used to infer causality. We have studied only men, and the data may not necessarily be generalizable to females with T1D.

The strength of the study is that skeletal properties were assessed with several methods targeting different aspects of bone quality. Studies on bone affection in men with T1D are limited, and it is time to address this. Finally, the burden of other diabetic complications was relatively low, enabling us to show that the bone affection occurs independent of this.

In conclusion, we demonstrate by use of in vivo IMI that bone material properties are compromised in men with T1D. We also show impaired bone microarchitecture assessed by TBS. Our findings underscore the need for increased awareness of bone as a target for diabetic complications.

\section{Supplementary materials}

This is linked to the online version of the paper at https://doi.org/10.1530/ EC-21-0193.

\section{Declaration of interest}

The authors declare that there is no conflict of interest that could be perceived as prejudicing the impartiality of the research reported.

\section{Funding}

This study was supported by grants from the Liaison Committee between the Central Norway Regional Health Authority and the Norwegian University of Science and Technology.

\section{Author contribution statement}

$\mathrm{US}, \mathrm{M} \mathrm{P} M$ and A K S contributed to the conception and design of the study and interpretation of the data. U S and A K S drafted the manuscript. A K S performed the statistical analyses. All authors contributed to the acquisition of data and to critical revision. $U S$ is the guarantor of this work and, as such, had full access to all the data in the study and takes responsibility for the integrity of the data and the accuracy of the data analysis.

\section{References}

1 Shah VN, Shah CS \& Snell-Bergeon JK. Type 1 diabetes and risk of fracture: meta-analysis and review of the literature. Diabetic Medicine 201532 1134-1142. (https://doi.org/10.1111/dme.12734)

2 Bai J, Gao Q, Wang C \& Dai J. Diabetes mellitus and risk of low-energy fracture: a meta-analysis. Aging Clinical and Experimental Research 2020 32 2173-2186. (https://doi.org/10.1007/s40520-019-01417-x)

3 Napoli N, Chandran M, Pierroz DD, Abrahamsen B, Schwartz AV, Ferrari SL \& IOF Bone and Diabetes Working Group. Mechanisms of diabetes mellitus-induced bone fragility. Nature Reviews: Endocrinology 201713 208-219. (https://doi.org/10.1038/nrendo.2016.153)

4 Vestergaard P. Discrepancies in bone mineral density and fracture risk in patients with type 1 and type 2 diabetes: a meta-analysis. Osteoporosis International 200718 427-444. (https://doi.org/10.1007/ s00198-006-0253-4)

5 Chavassieux P, Seeman E \& Delmas PD. Insights into material and structural basis of bone fragility from diseases associated with fractures: how determinants of the biomechanical properties of bone are compromised by disease. Endocrine Reviews 200728 151-164. (https://doi.org/10.1210/er.2006-0029)

6 Seeman E \& Delmas PD. Bone quality: the material and structural basis of bone strength and fragility. New England Journal of Medicine 2006 354 2250-2261. (https://doi.org/10.1056/NEJMra053077)

7 Hans D, Goertzen AL, Krieg MA \& Leslie WD. Bone microarchitecture assessed by TBS predicts osteoporotic fractures independent of bone density: the Manitoba study. Journal of Bone and Mineral Research 2011 26 2762-2769. (https://doi.org/10.1002/jbmr.499)

8 Popp AW, Buffat H, Eberli U, Lippuner K, Ernst M, Richards RG, Stadelmann VA \& Windolf M. Microstructural parameters of bone evaluated using HR-pQCT correlate with the DXA-derived cortical index and the trabecular bone score in a cohort of randomly selected premenopausal women. PLoS ONE 20149 e88946. (https://doi. org/10.1371/journal.pone.0088946)

9 Schoeb M, Hamdy NAT, Malgo F, Winter EM \& Appelman-Dijkstra NM. Added value of impact microindentation in the evaluation of bone fragility: a systematic review of the literature. Frontiers in Endocrinology 202011 15. (https://doi.org/10.3389/fendo.2020.00015)

10 Murray CE \& Coleman CM. Impact of diabetes mellitus on bone health. International Journal of Molecular Sciences 2019204873. (https://doi.org/10.3390/ijms20194873)

11 Saito M \& Marumo K. Collagen cross-links as a determinant of bone quality: a possible explanation for bone fragility in aging, osteoporosis, and diabetes mellitus. Osteoporosis International 201021 195-214. (https://doi.org/10.1007/s00198-009-1066-z)

12 Farlay D, Armas LA, Gineyts E, Akhter MP, Recker RR \& Boivin G. Nonenzymatic glycation and degree of mineralization are higher in bone from fractured patients with type 1 diabetes mellitus. Journal of Bone and Mineral Research 201631 190-195. (https://doi.org/10.1002/ jbmr.2607)

13 Neumann T, Lodes S, Kastner B, Franke S, Kiehntopf M, Lehmann T, Muller UA, Wolf G \& Samann A. High serum pentosidine but not esRAGE is associated with prevalent fractures in type 1 diabetes independent of bone mineral density and glycaemic control. Osteoporosis International 201425 1527-1533. (https://doi.org/10.1007/ s00198-014-2631-7)

14 Issa C, Zantout MS \& Azar ST. Osteoporosis in men with diabetes mellitus. Journal of Osteoporosis 20112011 651867. (https://doi. org/10.4061/2011/651867)

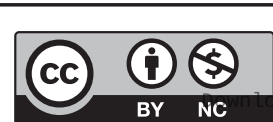

This work is licensed under a Creative Commons Attribution-NonCommercial 4.0 International License. ded from Bioscientifica com at 04/26/2023 10:44:24AM 
15 Neumann T, Lodes S, Kastner B, Lehmann T, Hans D, Lamy O, Muller UA, Wolf G \& Samann A. Trabecular bone score in type 1 diabetes: a cross-sectional study. Osteoporosis International 201627 127-133. (https://doi.org/10.1007/s00198-015-3222-y)

16 Ishikawa K, Fukui T, Nagai T, Kuroda T, Hara N, Yamamoto T, Inagaki K $\&$ Hirano T. Type 1 diabetes patients have lower strength in femoral bone determined by quantitative computed tomography: a crosssectional study. Journal of Diabetes Investigation 2015 726-733. (https://doi.org/10.1111/jdi.12372)

17 Kuroda T, Ishikawa K, Nagai T, Fukui T, Hirano T \& Inagaki K. Quadrant analysis of quantitative computed tomography scans of the femoral neck reveals superior region-specific weakness in young and middle-aged men with type 1 diabetes mellitus. Journal of Clinical Densitometry 201821 172-178. (https://doi.org/10.1016/j. jocd.2017.01.005)

18 Vermeulen A, Verdonck L \& Kaufman JM. A critical evaluation of simple methods for the estimation of free testosterone in serum. Journal of Clinical Endocrinology and Metabolism 199984 3666-3672. (https://doi.org/10.1210/jcem.84.10.6079)

19 Bridges D, Randall C \& Hansma PK. A new device for performing reference point indentation without a reference probe. Review of Scientific Instruments 201283 044301. (https://doi. org/10.1063/1.3693085)

20 Hadjidakis DJ, Raptis AE, Sfakianakis M, Mylonakis A \& Raptis SA. Bone mineral density of both genders in Type 1 diabetes according to bone composition. Journal of Diabetes and its Complications 200620 302-307. (https://doi.org/10.1016/j.jdiacomp.2005.07.006)

21 Janghorbani M, Van Dam RM, Willett WC \& Hu FB. Systematic review of type 1 and type 2 diabetes mellitus and risk of fracture. American Journal of Epidemiology 2007166 495-505. (https://doi.org/10.1093/ aje/kwm106)

22 Pan H, Wu N, Yang T \& He W. Association between bone mineral density and type 1 diabetes mellitus: a meta-analysis of cross-sectional studies. Diabetes/Metabolism Research and Reviews 201430 531-542. (https://doi.org/10.1002/dmrr.2508)

23 Ho-Pham LT \& Nguyen TV. Association between trabecular bone score and type 2 diabetes: a quantitative update of evidence. Osteoporosis International 201930 2079-2085. (https://doi.org/10.1007/s00198-01905053-z)

24 Karytska N, Dydyshka Y, Shepelkevich A, Vasilyeva N, Vadzianava V \& Zhukouskaya V. Evaluation of trabecular bone score in men with type 1 diabetes. Endocrine Abstracts 201963 P100. (https://doi.org/10.1530/ endoabs.63.P100)

25 Shah VN, Sippl R, Joshee P, Pyle L, Kohrt WM, Schauer IE \& SnellBergeon JK. Trabecular bone quality is lower in adults with type 1 diabetes and is negatively associated with insulin resistance. Osteoporosis International 201829 733-739. (https://doi.org/10.1007/ s00198-017-4353-0)

26 Farr JN, Drake MT, Amin S, Melton LJ, 3rd, McCready LK \& Khosla S In vivo assessment of bone quality in postmenopausal women with type 2 diabetes. Journal of Bone and Mineral Research 201429 787-795. (https://doi.org/10.1002/jbmr.2106)

27 Furst JR, Bandeira LC, Fan WW, Agarwal S, Nishiyama KK, McMahon DJ, Dworakowski E, Jiang H, Silverberg SJ \& Rubin MR. Advanced glycation endproducts and bone material strength in Type 2 diabetes. Journal of Clinical Endocrinology and Metabolism 2016101 2502-2510. (https://doi.org/10.1210/jc.2016-1437)

28 Nilsson AG, Sundh D, Johansson L, Nilsson M, Mellstrom D, Rudang R, Zoulakis M, Wallander M, Darelid A \& Lorentzon M. Type 2 diabetes mellitus is associated with better bone microarchitecture but lower bone material strength and poorer physical function in elderly women: a population-based study. Journal of Bone and Mineral Research 201732 1062-1071. (https://doi.org/10.1002/jbmr.3057)
29 Holloway-Kew KL, Betson A, Rufus-Membere PG, Gaston J, DiezPerez A, Kotowicz MA \& Pasco JA. Impact microindentation in men with impaired fasting glucose and type 2 diabetes. Bone 2021142 115685. (https://doi.org/10.1016/j.bone.2020.115685)

30 Ballesta S, Guerri-Fernandez RC, Chillaron JJ, Guell A, Herrera S, Torres E, Ascoeta NG, Flores Le-Roux JA \& Diez A. The use of microindentation for the study of bone properties in type 1 diabetes mellitus patients. Osteoporosis International 202031 175-180. (https:// doi.org/10.1007/s00198-019-05178-1)

31 Hygum K, Starup-Linde J, Harsløf T, Vestergaard P \& Langdahl BL. Mechanisms in endocrinology: diabetes mellitus, a state of low bone turnover-a systematic review and meta-analysis. European Journal of Endocrinology 2017 176 R137-R157. (https://doi.org/10.1530/EJE-16-0652)

32 Hie M, Iitsuka N, Otsuka T \& Tsukamoto I. Insulin-dependent diabetes mellitus decreases osteoblastogenesis associated with the inhibition of Wnt signaling through increased expression of Sost and Dkk1 and inhibition of Akt activation. International Journal of Molecular Medicine 201128 455-462. (https://doi.org/10.3892/ijmm.2011.697)

33 Faienza MF, Ventura A, Delvecchio M, Fusillo A, Piacente L, Aceto G Colaianni G, Colucci S, Cavallo L, Grano M, et al. High sclerostin and Dickkopf-1 (DKK-1) serum levels in children and adolescents with type 1 diabetes mellitus. Journal of Clinical Endocrinology and Metabolism 2017102 1174-1181. (https://doi.org/10.1210/jc.2016-2371)

34 Pacicca DM, Brown T, Watkins D, Kover K, Yan Y, Prideaux M \& Bonewald L. Elevated glucose acts directly on osteocytes to increase sclerostin expression in diabetes. Scientific Reports 2019917353. (https://doi.org/10.1038/s41598-019-52224-3)

35 Yang X, Mostafa AJ, Appleford M, Sun LW \& Wang X. Bone formation is affected by matrix advanced glycation end products (AGEs) in vivo. Calcified Tissue International 201699 373-383. (https://doi.org/10.1007/ s00223-016-0153-3)

36 Vaculik J, Braun M, Dungl P, Pavelka K \& Stepan JJ. Serum and bone pentosidine in patients with low impact hip fractures and in patients with advanced osteoarthritis. BMC Musculoskeletal Disorders 201617 308. (https://doi.org/10.1186/s12891-016-1168-7)

37 Asadipooya K \& Uy EM. Advanced glycation end products (AGEs), receptor for AGEs, diabetes, and bone: review of the literature. Journal of the Endocrine Society 20193 1799-1818. (https://doi.org/10.1210/ js.2019-00160)

38 Hofbauer LC, Brueck CC, Singh SK \& Dobnig H. Osteoporosis in patients with diabetes mellitus. Journal of Bone and Mineral Research 200722 1317-1328. (https://doi.org/10.1359/jbmr.070510)

39 Bortolin RH, Freire Neto FP, Arcaro CA, Bezerra JF, da Silva FS, Ururahy MA, Souza KS, Lima VM, Luchessi AD, Lima FP, et al. Anabolic effect of insulin therapy on the bone: osteoprotegerin and osteocalcin up-regulation in streptozotocin-induced diabetic rats. Basic and Clinical Pharmacology and Toxicology 2017120 227-234. (https://doi. org/10.1111/bcpt.12672)

40 Ivaska KK, Heliövaara MK, Ebeling P, Bucci M, Huovinen V, Väänänen HK, Nuutila P \& Koistinen HA. The effects of acute hyperinsulinemia on bone metabolism. Endocrine Connections 20154 155-162. (https://doi.org/10.1530/EC-15-0022)

41 Rude RK. Magnesium deficiency and diabetes mellitus: causes and effects. Postgraduate Medicine 199292 217-219, 222-224. (https://doi. org/10.1080/00325481.1992.11701494)

42 Kunutsor SK, Whitehouse MR, Blom AW \& Laukkanen JA. Low serum magnesium levels are associated with increased risk of fractures: a long-term prospective cohort study. European Journal of Epidemiology 201732 593-603. (https://doi.org/10.1007/s10654-017-0242-2)

43 Castiglioni S, Cazzaniga A, Albisetti W \& Maier JA. Magnesium and osteoporosis: current state of knowledge and future research directions. Nutrients 20135 3022-3033. (https://doi.org/10.3390/ nu5083022) https://ec.bioscientifica.com https://doi.org/10.1530/EC-21-0193 (c) 2021 The authors Published by Bioscientifica Ltd

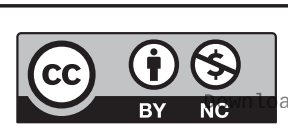

This work is licensed under a Creative Commons Attribution-NonCommercial 4.0 International License. ded from Bioscientifica.com at 04/26/2023 10:44:24AM 
44 Bigi A, Foresti E, Gregorini R, Ripamonti A, Roveri N \& Shah JS. The role of magnesium on the structure of biological apatites. Calcified Tissue International 199250 439-444. (https://doi.org/10.1007/BF00296775)

45 Starup-Linde J \& Vestergaard P. Biochemical bone turnover markers in diabetes mellitus: a systematic review. Bone 201682 69-78. (https:// doi.org/10.1016/j.bone.2015.02.019)

46 Wang Z, Li Y, Zhou F, Piao Z \& Hao J. Effects of statins on bone mineral density and fracture risk: a PRISMA-compliant systematic review and meta-analysis. Medicine 201695 e3042. (https://doi.org/10.1097/ MD.0000000000003042)

47 Kwok T, Leung J, Zhang YF, Bauer D, Ensrud KE, Barrett-Connor E, Leung PC \& Osteoporotic Fractures in Men (MrOS) Research Group. Does the use of ACE inhibitors or angiotensin receptor blockers affect bone loss in older men? Osteoporosis International 201223 2159-2167. (https://doi.org/10.1007/s00198011-1831-7)

Received in final form 28 June 2021

Accepted 21 July 2021

Accepted Manuscript published online 21 July 2021
This work is licensed under a Creative Commons Attribution-NonCommercial 4.0 International License. 